\title{
CLINICAL MEANING OF INCOMPETENT PERFORATORS IN THE SETTING OF POST-THROMBOTIC SYNDROME COMMENTARY
}

\author{
Marian Simka \\ Department of Nursing, College of Applied Sciences, Ruda Śląska, Poland
}

\author{
EDITORIAL COMMENTARY \\ Phlebological Review 2015; 23, 2: 60-61 \\ DOI: $10.5114 /$ pr.2015.54037
}

In this issue of Phlebological Review Zolotukhin et al. [1] present the results of their study on recurrence of venous leg ulcers in post-thrombotic patients after endovenous laser ablation of incompetent lower leg perforators. They have found that not only the recurrence rate of these perforators was very high, but also that the procedure did not reduce the ulcer recurrence.

This lack of clinical efficacy in terms of recurrence was different from the results of the well-known ESCHAR study [2]. In the ESCHAR study surgical ablation of incompetent superficial veins resulted in less frequent recurrences. From a hemodynamic and pathophysiological point of view a thermal ablation (such as laser endovenous treatment) should not differ greatly from surgical removal of incompetent veins. However, in the ESCHAR study ulcer patients presented with superficial vein pathology, while in this study the main pathology concerned deep veins (with a possible additional burden associated with incompetent perforators). At the moment there are two different and conflicting opinions regarding lower leg perforators. Most phlebologists believe that incompetent perforating veins allow venous outflow from the deep venous system into superficial veins, which in turn evokes venous congestion in subcutaneous veins. Others, however, argue that actually the so-called incompetent perforators allow blood refluxing in incompetent superficial veins to re-enter the deep venous system, thus decongesting superficial veins [3-8].

A body of evidence supports both opinions. On one hand it is known that bi-directional flow in perforating veins is more common in venous patients than in normal subjects, that the number of incompetent perforators and their diameter increases with the severity of chronic venous disease, and that patients with recurrent varicose veins have both a higher prevalence and a greater number of incompetent perforating veins than patients with primary varicose veins. All of these observations suggest that refluxing perforators play a pathological role. On the other hand, it is known that incompetent perforating veins are usually associated with reflux in the superficial veins, indicating that deep venous reflux is rarely the primary cause of insufficiency of these perforators, that residual varicose veins after varicose vein surgery are not significantly related to the presence of pre-operatively incompetent perforators, and that treatment of incompetent superficial veins concomitantly corrects a significant proportion of incom- petent perforators. One may argue that beneficial results of subfascial ablation of incompetent perforators (the so-called SEPS procedure) confirm the pathological role of perforators in leg ulcer patients [9]. However, although the SEPS procedure improves healing rates and lowers the ulcer recurrence rate, it remains unclear if this clinical benefit is the result of surgical management of the perforators, or is related to ablation of incompetent superficial veins. Indeed, ulcer healing and ulcer recurrence rates after SEPS are similar to those after compression therapy alone [10, 11]. Besides, a similar beneficial effect of the CHIVA procedure, where the perforators are not addressed [12], suggests that perforators actually play a minor, if any, role in the settings of coexisting superficial incompetence.

Patients with post-thrombotic syndrome are probably different from those with predominant superficial incompetence. It is already known that the recurrence rate of incompetent perforators is very high, both after low-invasive treatments and after surgical ligation. It is also known that recurrence of ulcers is particularly high in post-thrombotic limbs [13-15], even after invasive management of perforators. Therefore, even if in selected cases of post-thrombotic syndrome these perforators should be managed (especially if they are the only source of reflux feeding the varicose veins and are likely to transmit a high venous pressure from the deep veins to the veins of the skin), it should be acknowledged that many of them will recur, irrespective of the method used for their closure, and that clinical improvement will not be permanent. Perhaps post-thrombotic patients with leg ulcers after invasive treatment of incompetent perforators should be prospectively screened (probably every few months) and redo procedures should be considered in the case of recurrent incompetence. Future research should answer the question of whether such an active management would add any clinical benefit. It is also possible that we should accept the fact that post-thrombotic patients will suffer from recurrent ulcers irrespective of the treatment of incompetent perforating veins.

\section{References}

1. Zolotukhin I., Seliverstov E., Khabazova K., An E., Lebedev I. Endovenous laser ablation of incompetent calf perforating veins does not prevent recurrence of venous ulcers in patients with postthrombotic syndrome. Phlebol Rev 2015; 23: 54-59. 
2. Barwell J.R., Davies C.E., Deacon J., Harvey K., Minor J., Sassano A., Taylor M., Usher J., Wakely C., Earnshaw J.J., Heather B.P., Mitchell D.C., Whyman M.R., Poskitt K.R. Comparison of surgery and compression with compression alone in chronic venous ulceration (ESCHAR study): randomised controlled trial. Lancet 2004; 363: 1854-1859.

3. Burnand K.G., O'Donnell T.F. Jr, Thomas M.L., Browse N.L. The relative importance of incompetent communicating veins in the production of varicose veins and venous ulcers. Surgery 1977; 82: 9-13.

4. Labropoulos N., Leon L., RodriguezH., Kang S.S., Mansour A.M., Littooy F.N. Deep venous reflux and incompetent perforators: significance and implications for therapy. Phlebology 2004; 19: 22-27.

5. Reček Č. A critical appraisal of the role of ankle perforators for the genesis of venous ulcers in the lower leg. J Cardiovasc Surg (Torino) 1971; 12: 45-49.

6. Reček Č. The hemodynamic role of calf perforators. Phlebol Rev 2014; 22: 45-48.

7. Sarin S., Scurr J.H., Smith P.D. Medial calf perforators in venous disease: the significance of outward flow. J Vasc Surg 1992; 16 : 40-46.

8. Simka M. Lower leg perforators in human health and disease. Phlebol Rev 2014; 22: 49.

9. Kalra M., Gloviczki P., Noel A.A., Rooke T.W., Lewis B.D., Jenkins G.D., Canton L.G., Panneton J.M. Subfascial endoscopic perforator vein surgery in patients with post-thrombotic venous insufficiency - is it justified? Vasc Endovascular Surg 2002; 36: 41-50.

10. Gloviczki P., Bergan J.J., Rhodes J.M., Canton L.G., Harmsen S., Ilstrup D.M. Mid-term results of endoscopic perforator vein interruption for chronic venous insufficiency: lessons learned from the North American subfascial endoscopic perforator surgery registry. The North American Study Group. J Vasc Surg 1999; 29: 489-502.

11. Neglén P. Invasive treatment of post-thrombotic symptoms. Phlebolymphology 2006; 13: 163-171.

12. Zamboni P., Cisno C., Marchetti F., Mazza P., Fogato L., Carandina S., De Palma M., Liboni A. Minimally invasive surgical management of primary venous ulcers vs. compression treatment: a randomized clinical trial. Eur J Vasc Endovasc Surg 2003; 25: 313-318.

13. Franks P.J., Moffatt C.J., Connolly M. Factors associated with healing leg ulceration with high compression. Age Ageing 1995; 24: 407-410.

14. Moffatt C.J., Doherty D.C., Smithdale R., Franks P.J. Clinical predictors of leg ulcer healing. Br J Dermatol 2010; 162: 51-58.

15. Simka M. Prognostic factors for delayed healing of venous leg ulcers. Phlebol Rev 2014; 22: 58-61. 